\title{
Five different colours solid-state fluorescence of azastilbenes: a new push-pull $\pi$-conjugated system
}

\author{
PUMSAK RUANWAS ${ }^{\mathbf{1}}$, NAWONG BOONNAK ${ }^{2}$ and SUCHADA CHANTRAPROMMA ${ }^{1, *}$ \\ ${ }^{1}$ Department of Chemistry and Center of Excellence for Innovation in Chemistry, Faculty of Science, Prince of Songkla \\ University, Hat-Yai, Songkhla 90112, Thailand \\ ${ }^{2}$ Department of Chemistry, Faculty of Science, Thaksin University, Pattalung 93110, Thailand
}

MS received 16 May 2014; revised 1 September 2014

\begin{abstract}
Five push-pull azastilbene derivatives [R = -OH (1), $-\mathrm{OCH}_{3}(2),-\mathrm{OCH}_{2} \mathrm{CH}_{3}(3),-\mathrm{N}\left(\mathrm{CH}_{3}\right)_{2}(4)$ and $-\mathrm{N}\left(\mathrm{CH}_{2} \mathrm{CH}_{3}\right)_{2}$ (5)] have been synthesized and successfully characterized by ${ }^{1} \mathrm{H}$ NMR, ultraviolet-visible (UV-Vis) and Fourier-transform infrared (FT-IR) spectroscopy. Compounds 1-5 possess solid-state fluorescence in five different colours ranging from blue to orange $\left(\lambda_{\mathrm{ex}}\right.$ at $\left.400 \mathrm{~nm}\right)$ in which blue $\left(\lambda_{\mathrm{em}}\right.$ at $\left.474 \mathrm{~nm}\right)$ for 1 , bright-blue $\left(\lambda_{\mathrm{em}}\right.$ at $\left.469 \mathrm{~nm}\right)$ for 2 , green $\left(\lambda_{\mathrm{em}}\right.$ at $\left.537 \mathrm{~nm}\right)$ for 3 , yellow $\left(\lambda_{\mathrm{em}}\right.$ at $\left.568 \mathrm{~nm}\right)$ for 4 and orange $\left(\lambda_{\mathrm{em}}\right.$ at $\left.540,630 \mathrm{~nm}\right)$ for 5. Compounds 4 and 5 exhibited strong fluorescence with quantum yield values 0.61 and 0.84 , respectively, higher than those of 1-3. Moreover, liquid-state fluorescence performed in non-polar solvent in order to investigate the effect of dipolar intermolecular interactions on their fluorescence properties, the results revealed that the emission spectra of 1-5 in liquid state are similar to those of solid state, indicating that no significant dipolar interactions were observed. Therefore, the substituent with electron-donating group as $\mathbf{N}$ - or $\mathrm{O}$-donor and electron-withdrawing group as $-\mathrm{SO}_{3} \mathrm{H}$, on the azastilbene skeleton play a major role on their solid-state fluorescence.
\end{abstract}

Keywords. Dipole interaction; multi-colour fluorescence; push-pull azastilbene; quantum yield; solid-state fluorescence.

\section{Introduction}

Organic solid-state fluorescence materials have been attracted a great deal of interest in various electronic and photonic applications such as semiconductor lasers, ${ }^{1}$ fluorescence sensors, ${ }^{2}$ fluorescent technology, ${ }^{3}$ nonlinear optics, ${ }^{4}$ organic light-emitting diodes (OLEDs $)^{5}$ and optoelectronic devices. ${ }^{6,7}$ One of the advantages of the organic solid-state fluorescence materials is the ability to tune and control of fluorescence colours. Many extensive studies have shown that organic materials exhibit a variety of fluorescent colours in the solid state (scheme 1) such as triphenylamine styryl dye (TMS1); ${ }^{8}$ 9,10-bis[(9,9-dialkylfluorene-2-yl)vinyl]anthracene derivatives (FLA-Cn) ${ }^{9}$ and diphenylamino-carbazole pyridinium dyes (OD). ${ }^{10}$ From these studies, it indicated that $\pi$-conjugated system influences the photonic properties of the compounds.

Stilbenes and azastilbenes are types of compounds which comprise the $\pi$-conjugated system in their molecules. Several of them exhibit interesting electronic and photonic properties. ${ }^{11-14}$ In addition, the previous report by Shirai and co-workers ${ }^{15}$ found that the substituents affect the photonic properties of the compounds. From the above mentioned, it led us to develop a new push-pull azastilbene fluorophore

\footnotetext{
*Author for correspondence (suchada.c@psu.ac.th)
}

(D- $\pi-\mathrm{A}$ system) exhibiting multi-colour fluorescence by introducing electron-donating group (EDG) on ring $\mathrm{A}$ and electron-withdrawing group (EWG) on ring $\mathrm{B}$ of azastilbene skeleton (see scheme 1). Herein, we report the synthesis of five push-pull azastilbenes with two kinds of EDGs in which $\mathrm{N}$-alkyl and O-alkyl groups and sulphonic acid as EWG. Their solid-state fluorescence properties were evaluated.

\section{Experimental}

\subsection{General experimental procedures}

All the chemical reagents and solvents were of analytical grade, purchased commercially and used without further purification. Melting points were determined on a FisherJohn melting point apparatus. Ultraviolet-visible (UV-Vis) absorption spectra were measured on a Shimadzu UV-2450. Fourier-transform infrared spectra (FT-IR) were recorded on a Perkin-Elmer FTS 165 Fourier-transform infrared spectrometer. The ${ }^{1} \mathrm{H}$ NMR spectra were recorded on $300 \mathrm{MHz}$ Bruker NMR Ultra Shield spectrometer in DMSO- $d_{6}$ with TMS as the internal standard. Chemical shifts reported in ppm are expressed in Hertz. Both solid- and liquid-states fluorescence excitation and emission spectra were recorded on a Perkin-Elmer LS 55 Luminescence Spectrometer. 


\section{$\mathrm{D}-\pi-\mathrm{A}$ system}
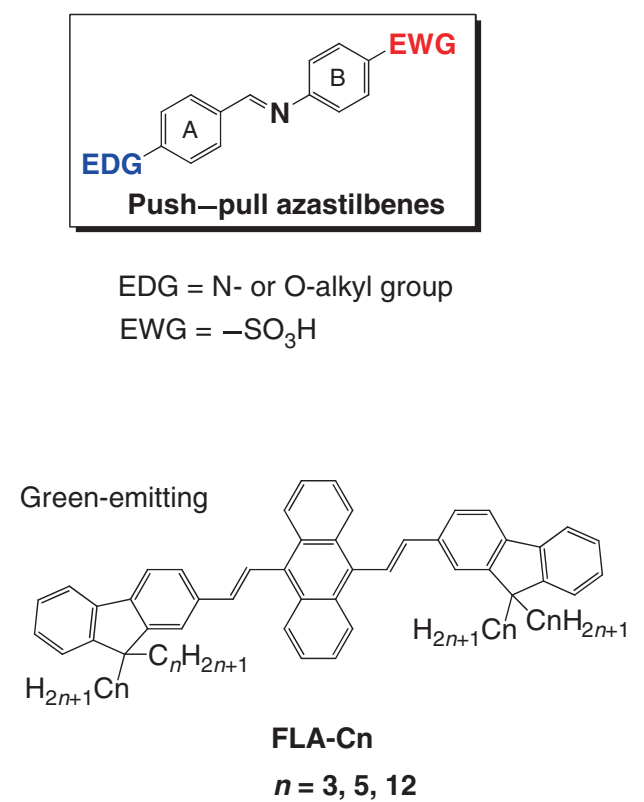
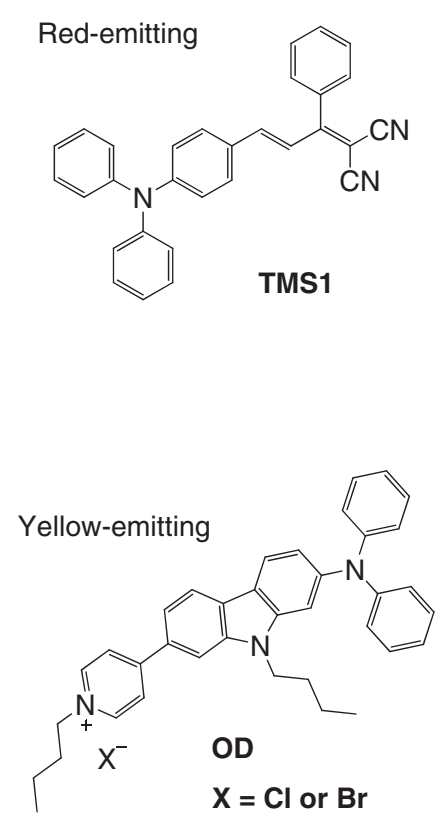

Scheme 1. The designed structure of push-pull azastilbenes and other $\pi$-conjugated compounds.

\subsection{Method of solid-and liquid-states fluorescence measurement}

The powder samples of each azastilbene compounds $(0.72 \mathrm{mmol})$ were heaped in the tray, covered with a quartz plate and then the solid-state fluorescence excitation and emission spectra were recorded on a Perkin-Elmer LS 55 Luminescence Spectrometer with slit width of $10 \mathrm{~nm}$ at the ambient temperature. Liquid-state fluorescence excitation and emission spectra of the clear solution of each azastilbene compound $(1.0 \mathrm{mmol})$ in tetrahydrofuran (THF) were performed on Perkin-Elmer LS 55 Luminescence Spectrometer with slit width of $10 \mathrm{~nm}$ at the ambient temperature. For emission spectra study, the excitation wavelength of both solid and liquid states was set at $400 \mathrm{~nm}$, as selected from their maximum UV-Vis absorption bands. The difference of relative intensities in reflection between the sample and $\mathrm{MgO}$ powder was calibrated using diffusion reflection in a non-absorbed wavelength, in the present case it is $650 \mathrm{~nm}$. Finally, fluorescence quantum yield $\left(\Phi_{\mathrm{f}}\right)$ was determined by Wrighton's method and calculated according to the below equation ${ }^{16}$

$$
\Phi_{\mathrm{f}}=j_{\mathrm{f}} /\left(\gamma j_{0}-j\right)
$$

where $j_{\mathrm{f}}$ is the fluorescence intensity of the sample, $\gamma$ the calibration factor (ranging over $0.85-0.97$ ), $j_{0}$ the backscattered intensity of excitation light from a blank (in the present case it is $\mathrm{MgO}$ ) and $j$ the back-scattered intensity of a loaded sample.

\subsection{Synthesis of azastilbene derivatives (1-5)}

A mixture of sulphanilic acid $(2.8 \mathrm{mmol})$ and each benzaldehyde derivative $(2.8 \mathrm{mmol})$, in which 4-hydroxybenzaldehyde for 1,4-methoxybenzaldehyde for 2,4-ethoxybenzaldehyde for 3, 4-dimethylaminobenzaldehyde for $\mathbf{4}$ and 4-diethylaminobenzaldehyde for 5, was dissolved in 3:1 water-methanol and stirred at $100^{\circ} \mathrm{C}$, and the reaction mixture was monitored by TLC. After $2 \mathrm{~h}$, the reaction was completed to give the azastilbene products as a precipitate, which was then filtrated and washed with distilled water. The obtained precipitate was further purified by recrystallization in ethanol to afford the desired azastilbene products $\mathbf{1}-\mathbf{5}$.

(E)-4-sulphonic-4'-hydroxyazastilbene (1): Yellow solid (92\% yield); $\mathrm{mp}>300^{\circ} \mathrm{C}$; UV-Vis (solid state) $\lambda_{\max }: 249$, $418 \mathrm{~nm}$; IR (KBr) $v_{\max }: 3430$ (O-H stretching), 3008 (C-H stretching), $1666(\mathrm{C}=\mathrm{N}$ stretching), $1379(\mathrm{~S}=\mathrm{O}$ stretching) $\mathrm{cm}^{-1}$. ${ }^{1} \mathrm{H}$ NMR (300 MHz, DMSO-d 6 ): $\delta 9.79(\mathrm{~s}, 1 \mathrm{H}$, $\mathrm{N}=\mathrm{CH}), 7.76(\mathrm{~d}, J=8.4 \mathrm{~Hz}, 2 \mathrm{H}, \mathrm{Ar}-\mathrm{H}), 7.65(\mathrm{~d}, J=$ $8.4 \mathrm{~Hz}, 2 \mathrm{H}, \mathrm{Ar}-\mathrm{H}), 7.19(\mathrm{~d}, J=8.4 \mathrm{~Hz}, 2 \mathrm{H}, \mathrm{Ar}-\mathrm{H})$ and $6.93(\mathrm{~d}, J=8.4 \mathrm{~Hz}, 2 \mathrm{H}, \mathrm{Ar}-\mathrm{H})$.

(E)-4-sulphonic-4'-methoxyazastilbene (2): Yellow solid ( $86 \%$ yield); $\mathrm{mp}>300^{\circ} \mathrm{C}$; UV-Vis (solid state) $\lambda_{\max }: 285$, $410 \mathrm{~nm}$; IR (KBr) $v_{\max }: 3397$ (O-H stretching), 2965 (C-H stretching), $1671 \quad(\mathrm{C}=\mathrm{N}$ stretching), $1348 \quad(\mathrm{~S}=\mathrm{O}$ stretching), 1004 (C-O stretching) $\mathrm{cm}^{-1} \cdot{ }^{1} \mathrm{H} \quad \mathrm{NMR}$ (300 MHz, DMSO- $\left.d_{6}\right): \quad \delta 9.87 \quad(\mathrm{~s}, \quad 1 \mathrm{H}, \quad \mathrm{N}=\mathrm{CH})$, $7.88(\mathrm{~d}, J=8.7 \mathrm{~Hz}, 2 \mathrm{H}, \operatorname{Ar}-\mathrm{H}), 7.67(\mathrm{~d}, J=$ $8.7 \mathrm{~Hz}, 2 \mathrm{H}, \mathrm{Ar}-\mathrm{H}), 7.27$ (d, $J=8.7 \mathrm{~Hz}, 2 \mathrm{H}, \mathrm{Ar}-\mathrm{H}), 7.13$ (d, $J=8.7 \mathrm{~Hz}, 2 \mathrm{H}, \mathrm{Ar}-\mathrm{H})$ and $3.87\left(\mathrm{~s}, 3 \mathrm{H},-\mathrm{OCH}_{3}\right)$.

(E)-4-sulphonic-4'-ethoxyazastilbene (3): Yellow solid (93\% yield); $\mathrm{mp}>300^{\circ} \mathrm{C}$; UV-Vis (solid state) $\lambda_{\max }: 275$, $434 \mathrm{~nm}$; IR (KBr) $v_{\max }$ : 3403 (O-H stretching), 2987 (C-H stretching), $1654(\mathrm{C}=\mathrm{N}$ stretching), 1368 ( $\mathrm{S}=\mathrm{O}$ stretching), 1140 (C-O stretching) $\mathrm{cm}^{-1}$. ${ }^{1} \mathrm{H}$ NMR $(300 \mathrm{MHz}$, DMSO$\left.d_{6}\right): \delta 9.86(\mathrm{~s}, 1 \mathrm{H}, \mathrm{N}=\mathrm{CH}), 7.86(\mathrm{~d}, J=8.7 \mathrm{~Hz}, 2 \mathrm{H}, \mathrm{Ar}-\mathrm{H})$, $7.68(\mathrm{~d}, J=8.7 \mathrm{~Hz}, 2 \mathrm{H}, \mathrm{Ar}-\mathrm{H}), 7.23(\mathrm{~d}, J=8.7 \mathrm{~Hz}, 2 \mathrm{H}$, 
Ar-H), 7.11 (d, $J=8.7 \mathrm{~Hz}, 2 \mathrm{H}, \mathrm{Ar}-\mathrm{H}), 4.15$ (q, $J=6.9 \mathrm{~Hz}$, $\left.2 \mathrm{H},-\mathrm{OCH}_{2}-\right)$ and $1.36\left(\mathrm{t}, J=6.9 \mathrm{~Hz}, 3 \mathrm{H},-\mathrm{CH}_{3}\right)$.

(E)-4-sulphonic-4'-dimethylaminoazastilbene (4): Orange solid (95\% yield); $\mathrm{mp}>300^{\circ} \mathrm{C}$; UV-Vis (solid state) $\lambda_{\max }$ : 280, $443 \mathrm{~nm}$; IR (KBr) $v_{\max }$ : 3435 (O-H stretching), 2912 (C-H stretching), 1655 ( $\mathrm{C}=\mathrm{N}$ stretching), $1371(\mathrm{~S}=\mathrm{O}$ stretching) $\mathrm{cm}^{-1} .{ }^{1} \mathrm{H}$ NMR $\left(300 \mathrm{MHz}, \mathrm{DMSO}-d_{6}\right): \delta 9.67$ (s, 1H, N=CH), $7.69(\mathrm{~d}, J=8.7 \mathrm{~Hz}, 2 \mathrm{H}, \mathrm{Ar}-\mathrm{H}), 7.57$ $(\mathrm{d}, J=8.7 \mathrm{~Hz}, 2 \mathrm{H}, \mathrm{Ar}-\mathrm{H}), 7.04(\mathrm{~d}, J=8.7 \mathrm{~Hz}, 2 \mathrm{H}, \mathrm{Ar}-\mathrm{H})$, $6.79(\mathrm{~d}, J=8.7 \mathrm{~Hz}, 2 \mathrm{H}, \mathrm{Ar}-\mathrm{H})$ and $3.05\left(\mathrm{~s}, 6 \mathrm{H},-\mathrm{N}\left(\mathrm{CH}_{3}\right)_{2}\right)$.

(E)-4-sulphonic-4'-diethylaminoazastilbene (5): Orange solid (80\% yield); mp 267-268 ${ }^{\circ} \mathrm{C}$ (decomposed); UV-Vis (solid state) $\lambda_{\max }: 286,461 \mathrm{~nm}$; IR $(\mathrm{KBr}) v_{\max }: 3414(\mathrm{O}-\mathrm{H}$ stretching), 2977 (C-H stretching), 1654 ( $\mathrm{C}=\mathrm{N}$ stretching), $1346\left(\mathrm{~S}=\mathrm{O}\right.$ stretching) $\mathrm{cm}^{-1} .{ }^{1} \mathrm{H}$ NMR $(300 \mathrm{MHz}, \mathrm{DMSO}-$ $\left.d_{6}\right): \delta 9.63(\mathrm{~s}, 1 \mathrm{H}, \mathrm{N}=\mathrm{CH}), 7.66(\mathrm{~d}, J=8.4 \mathrm{~Hz}, 2 \mathrm{H}, \mathrm{Ar}-\mathrm{H})$, $7.57(\mathrm{~d}, J=8.4 \mathrm{~Hz}, 2 \mathrm{H}, \mathrm{Ar}-\mathrm{H}), 7.05(\mathrm{~d}, J=8.4 \mathrm{~Hz}, 2 \mathrm{H}$, $\mathrm{Ar}-\mathrm{H}), 6.76(\mathrm{~d}, J=8.4 \mathrm{~Hz}, 2 \mathrm{H}, \mathrm{Ar}-\mathrm{H}), 3.44$ (q, $J=6.9 \mathrm{~Hz}$, $\left.4 \mathrm{H},-\mathrm{N}\left(\mathrm{CH}_{2}-\right)_{2}\right)$ and $1.13\left(\mathrm{t}, J=6.9 \mathrm{~Hz}, 6 \mathrm{H},-\left(\mathrm{CH}_{3}\right)_{2}\right)$.

\section{Results and discussion}

We reported the successful synthesis of push-pull azastilbene derivatives $\mathbf{1}-\mathbf{5}$, which were formed by condensation of benzaldehyde derivatives and sulphanilic acid as illustrated in scheme 2 .

FT-IR spectra of 1-5 exhibited a key vibration signal of the $\mathrm{C}=\mathrm{N}$ stretching at $1654-1671 \mathrm{~cm}^{-1}$ (see section 2). The ${ }^{1} \mathrm{H}$ NMR (300 MHz, DMSO- $d_{6}$ ) spectra of $\mathbf{1 - 5}$ also exhibited a singlet signal of an olefinic proton at $\delta 9.63-9.87 \mathrm{ppm}$ (see section 2) responsible for a signal of an imine part on the azastilbene skeleton, which indicated that the formation of desired azastilbene skeleton was successfully formed via condensation reaction.

The solid-state UV-Vis absorption spectra of 1-5 exhibited two key electronic transitions of $\pi-\pi^{*}$ and $n-\pi^{*}$ at 249-286 and 410-461 nm, respectively (see section 2 and figure 1a). The solid-state UV-Vis spectra of $\mathbf{4}$ and $\mathbf{5}$ also showed strong red-shifted absorption bands than 1-3. It could be suggested that $\mathrm{N}$-substituent group as $\mathrm{N}\left(\mathrm{CH}_{3}\right)_{2}$ and $\mathrm{N}\left(\mathrm{CH}_{2} \mathrm{CH}_{3}\right)_{2}$ for $\mathbf{4}$ and $\mathbf{5}$ posses electron donating ability than $\mathrm{O}$-substituent group as $\mathrm{OH}, \mathrm{OCH}_{3}$ and $\mathrm{OCH}_{2} \mathrm{CH}_{3}$ for 1-3, respectively, which caused the red-shift of the absorption

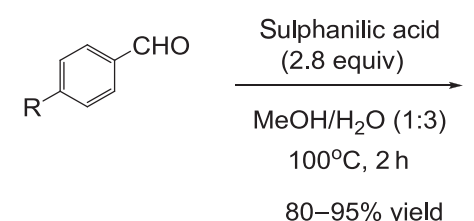

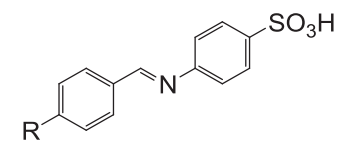

Push-pull azastilbenes

1: $\mathrm{R}=\mathrm{OH}$

2: $\mathrm{R}=\mathrm{OCH}_{3}$

3: $\mathrm{R}=\mathrm{OCH}_{2} \mathrm{CH}_{3}$

4: $\mathrm{R}=\mathrm{N}\left(\mathrm{CH}_{3}\right)_{2}$

5: $\mathrm{R}=\mathrm{N}\left(\mathrm{CH}_{2} \mathrm{CH}_{3}\right)_{2}$
Scheme 2. Synthesis of the push-pull azastilbenes 1-5. spectra. From the maximum absorbance of solid-state UVVis spectral data, the excitation wavelength was then set at $400 \mathrm{~nm}$ in order to study the solid-state fluorescence emission spectra.

From the solid-state fluorescence emission spectra of 1-5 in figure $1 \mathrm{~b}$ and table 1 , it showed that the push-pull azastilbenes 1-5 exhibited five different emission wavelengths $\left(\lambda_{\mathrm{em}}\right)$ in which $474 \mathrm{~nm}$ for $\mathbf{1}, 469 \mathrm{~nm}$ for $\mathbf{2}, 537 \mathrm{~nm}$ for 3, $568 \mathrm{~nm}$ for 4 and 540 and $630 \mathrm{~nm}$ for 5. In figure 1c, the appearance of fluorescence colours of 1-5 were performed under UV irradiation ( $\lambda_{\mathrm{ex}}$ at $365 \mathrm{~nm}$ ), the results showed that push-pull azastilbenes $\mathbf{1 - 5}$ emitted five different
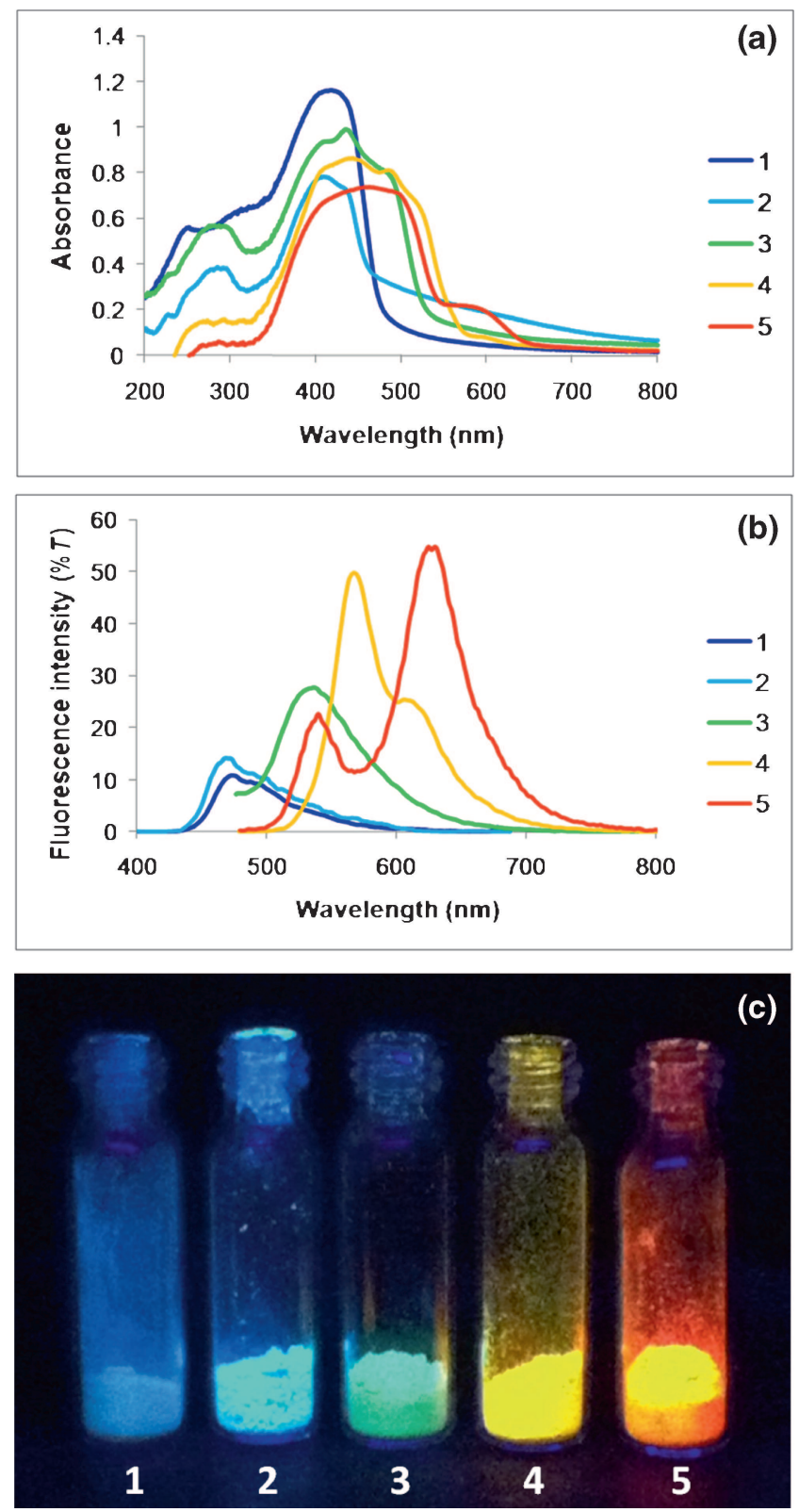

Figure 1. Photophysical properties of 1-5. (a) Solid-state UVVis absorption spectra. (b) Solid-state fluorescence emission spectra $\left(\lambda_{\text {ex }}\right.$ at $\left.400 \mathrm{~nm}\right)$. (c) The appearance fluorescence colour images under UV irradiation. 
Table 1. Solid-state photophysical data for $\mathbf{1 - 5}$.

\begin{tabular}{|c|c|c|c|c|c|c|c|}
\hline No. & $\mathrm{R}$ & $\lambda_{\mathrm{abs}}(\mathrm{nm})$ & $\lambda_{\mathrm{em}}(\mathrm{nm})$ & Fluorescence intensity & Stokes shift (nm) & Fluorescence colours & $\Phi_{\mathrm{f}}$ \\
\hline 1 & $-\mathrm{OH}$ & 418 & 474 & 10.87 & 56 & Blue & 0.12 \\
\hline 2 & $-\mathrm{OCH}_{3}$ & 410 & 469 & 14.08 & 59 & Bright-blue & 0.18 \\
\hline 3 & $-\mathrm{OCH}_{2} \mathrm{CH}_{3}$ & 434 & 537 & 27.62 & 103 & Green & 0.32 \\
\hline 4 & $-\mathrm{N}\left(\mathrm{CH}_{3}\right)_{2}$ & 443 & 568 & 49.83 & 125 & Yellow & 0.61 \\
\hline 5 & $-\mathrm{N}\left(\mathrm{CH}_{2} \mathrm{CH}_{3}\right)_{2}$ & 461 & $540,630 *$ & 54.80 & 169 & Orange & 0.84 \\
\hline
\end{tabular}

* Selected emission wavelength for Stoke shift calculation.

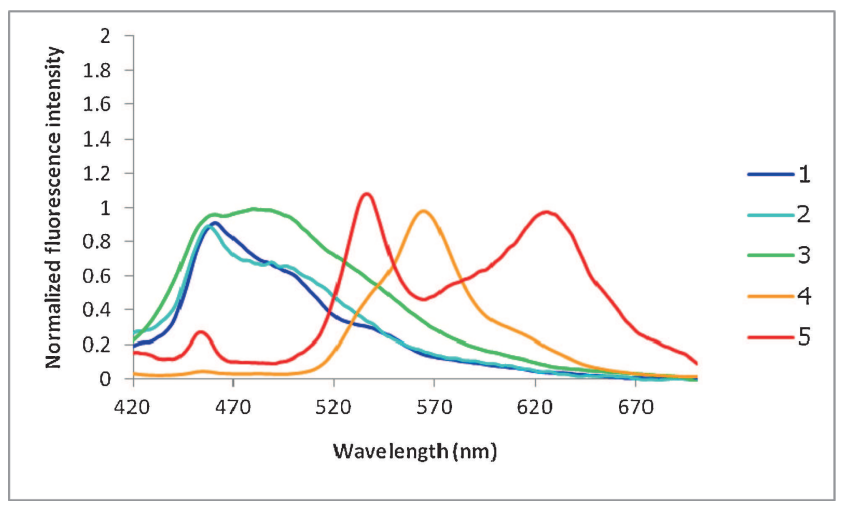

Figure 2. Liquid-state fluorescence emission spectra of $\mathbf{1}-\mathbf{5}$ in $\operatorname{THF}\left(\lambda_{\text {ex }}\right.$ at $\left.400 \mathrm{~nm}\right)$.

fluorescence colours ranging from blue to orange in which blue for $\mathbf{1}$, bright-blue for $\mathbf{2}$, green for $\mathbf{3}$, yellow for $\mathbf{4}$ and orange for $\mathbf{5}$, which corresponded to each of their emission wavelengths. The various fluorescence colours of 1-5 could be finely tuned by varying the donor substituent groups.
To determine the fluorescence efficiency, therefore fluorescence quantum yields of 1-5 were carried out as shown in table 1. It was found that $\mathrm{N}$-substituted azastilbenes $\mathbf{4}$ and 5 showed higher $\Phi_{\mathrm{f}}$ values with 0.61 and 0.84 , respectively, in comparison to those of O-substituted azastilbenes 1-3, indicating that $\mathrm{N}$-substituted groups could enhance the fluorescent intensity.

The presence of the sulphonic and imine parts on this class of molecules was expected that the dipolar intermolecular interactions could be formed self-organized architectures, which may cause their exhibited solid-state fluorescences. To investigate this interaction, the liquid-state fluorescence in non-polar solvent as THF was further performed. In figure 2, the liquid-state fluorescence spectra of 1-5 showed similar emission spectra to those observed in solid-state fluorescence, indicating that no significant dipolar interactions affect the solid-state fluorescence properties of $\mathbf{1 - 5} .{ }^{17}$

In addition, the crystal packing of $\mathbf{5}^{18}$ as shown in figure 3 is clearly seen that no $\pi-\pi$ interaction was observed in the solid state indicating by the centriod-centriod distances $(\mathrm{Cg}-\mathrm{Cg})$ between the amino- and sulphonic-substituted

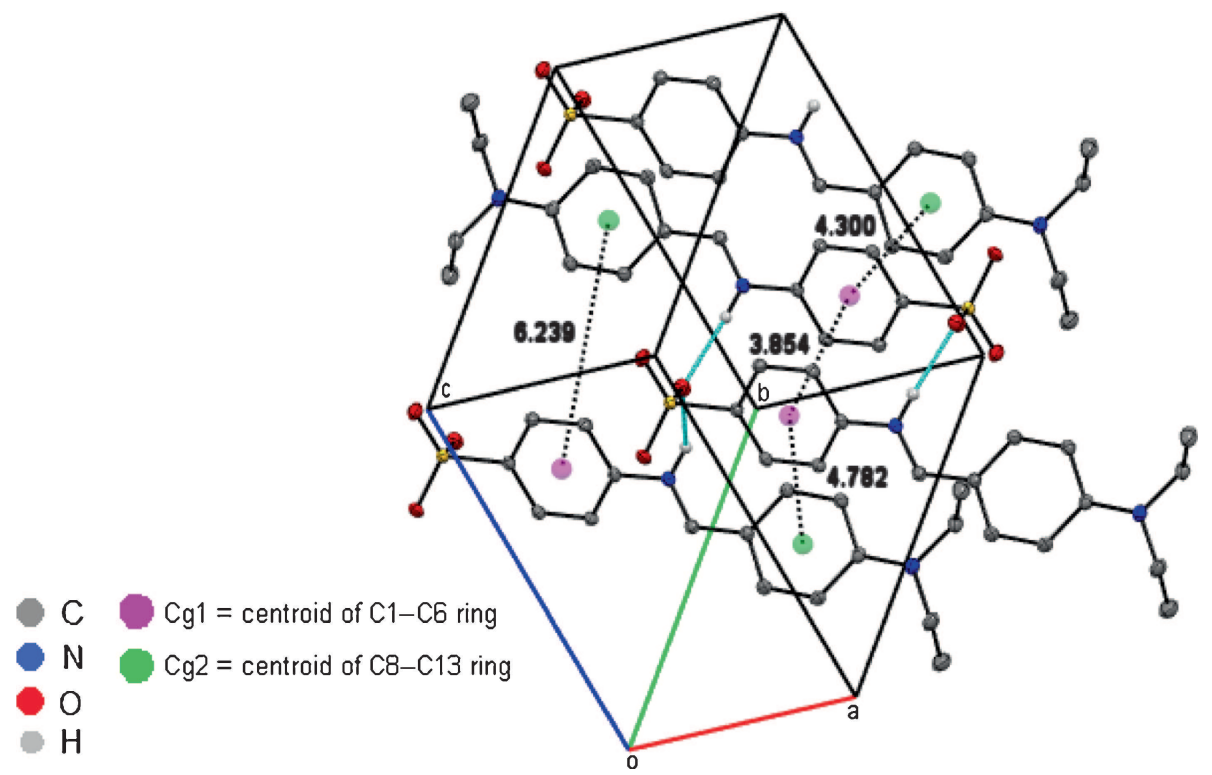

Figure 3. $\mathrm{Cg}-\mathrm{Cg}$ distances in the solid state of 5. Only $\mathrm{H}$ atom involved in hydrogen bonding was shown for clarity. 
phenyl rings $(\mathrm{Cg}-\mathrm{Cg}$ distances $=3.854(6)$, 4.300(6), $4.782(6)$ and $6.239(6) \AA)$ are out of ranges of the $\pi-\pi$ interaction $(3.3-3.8 \AA){ }^{19}$

From the above mention, it showed that substituents with electron-donating group as $\mathrm{N}$ - or O-donor and electronwithdrawing group as $-\mathrm{SO}_{3} \mathrm{H}$, on the azastilbene skeleton responsible for their solid-state fluorescence properties.

\section{Conclusion}

We have successfully synthesized and developed the five push-pull azastilbenes 1-5, which emit various fluorescence colours with promising quantum yields. Compounds 1-5 were synthesized in the quantitative yields (80-95\% yield) by condensation of sulphanilic acid and benzaldehyde derivatives. Interestingly that the solid-state fluorescence of 1-5 showed five different colours in range of blue to orange in which blue for $\mathbf{1}$, bright-blue for $\mathbf{2}$, green for $\mathbf{3}$, yellow for $\mathbf{4}$ and orange for $\mathbf{5}$. The results suggested that $\mathrm{N}$-substituted group on the azastilbene skeleton has a strong influence on their solid-state fluorescence. Therefore, electron-donating and electron-withdrawing groups on the azastilbene skeleton play a major role on their solid-state fluorescence properties. These synthesized push-pull azastilbenes could be good candidates for various photonic applications.

\section{Acknowledgements}

The authors thank the Thailand Research Fund through the Royal Golden Jubilee Ph.D. Program (Grant no. PHD/0314/2552), the Center of Excellence for Innovation in Chemistry (PERCH-CIC), Office of the Higher Education, Ministry of Education for financial support, and Prince of Songkla University for a research grant (SCI580911S).

\section{References}

1. Samuel I D W and Turnbull G A 2007 Chem. Rev. 1071272

2. Fei Z, Kocher N, Mohrschladt C J, Ihmels H and Stalke D 2003 Angew. Chem. Int. Ed. 42783

3. Jiao G S, Thoresen L H and Burgess K 2003 J. Am. Chem. Soc. 12514668

4. Derrar S N, Sekkal-Rahal M, Guemra K and Derreumaux P 2012 Int. J. Quant. Chem. 1122735

5. Lin Y, Chen Y, Ye T-L, Chen Z-K, Dai Y-F and Ma D-G 2012 J. Photochem. Photobiol., A Chem. 23055

6. Chung J W, Yang H, Singh B, Moon H B, An K S, Lee Y and Park S Y 2009 J. Mater. Chem. 195920

7. Huang J, Li C, Xia Y J, Zhu X H, Peng J B and Cao Y 2007 J. Org. Chem. 728520

8. Gupta V D, Tathe A B, Padalkar V S, Umape P G and Sekar N 2013 Dyes Pigm. 97429

9. Bu L, Sun M, Zhang D, Liu W, Wang Y, Zheng M, Xue S and Yang W 2013 J. Mater. Chem. 12028

10. Ooyama Y, Oda Y, Hagiwara Y, Fukuoka H, Miyazaki E, Mizumo T and Ohshita J 2013 Tetrahedron 695818

11. Ciorba S, Clennan E L, Mazzucato U and Spalletti A 2012 J. Lumin. 1311193

12. Lee K-H, Choi C-S and Jeon K-S 2002 J. Photochem. 971

13. Yoshino J, Kano N and Kawashima T 2009 J. Org. Chem. 74 7496

14. Zhu Y-C, He D-H and Yang Z-R 2009 Spectrochim. Acta A 72 417

15. Shirai K, Matsuoka M and Fukunishi K 2000 Dyes Pigm. 47 107

16. Wrighton M S, Ginley D S and Morse D L 1974 J. Phys. Chem. 782229

17. Refiker H and Icil H 2011 Turk. J. Chem. 35847

18. Ruanwas P, Chantrapromma S and Fun H-K 2012 Acta Crystallogr. $\mathbf{E 6 8}$ o2155

19. Janiak C 2000 J. Chem. Soc., Dalton Trans. 3885 